\title{
The Impact of Polymerization Technique and Glass-Fiber Reinforcement on the Flexural Properties of Denture Base Resin Material
}

\author{
Ahmad M. Al-Thobity ${ }^{1}$ \\ ${ }^{1}$ Department of Substitutive Dental Sciences, College of Dentistry, \\ Imam Abdulrahman Bin Faisal University, Dammam, Saudi Arabia
}

\begin{abstract}
Address for correspondence Ahmad M. Al-Thobity, BDS, MDS, FRCD (C), Department of Substitutive Dental Sciences, College of Dentistry, Imam Abdulrahman Bin Faisal University, Dammam,34212, Saudi Arabia (e-mail: aalthobity@iau.edu.sa).
\end{abstract}

\begin{abstract}
Keywords

- autoclave

- water bath

- polymerization

- glass fiber

- denture base

Objective Different polymerization and reinforcement techniques have been tested to enhance the mechanical characteristics of denture base acrylic resins. The goal of the present study was to evaluate the influence of autoclave polymerization techniques with glass fiber reinforcement on the flexural strength and elastic modulus of polymethyl methacrylate denture base resins.

Materials and Methods Ninety specimens were fabricated from heat-polymerized acrylic resin and randomly distributed depending on the polymerization technique into three groups $(n=30)$ : water bath polymerization, short-cycle autoclave polymerization, and long-cycle autoclave polymerization. Each group was further divided into three subgroups $(n=10)$ based on the concentration of glass fiber $0,2.5$, and $5 w t \%$. The flexural strength and elastic modulus were investigated using a universal testing machine. One-way ANOVA and Tukey's post hoc test were performed to analyze the results $(\alpha=0.05)$.

Results The flexural strength and elastic modulus values were significantly higher in $5 w t \%$ glass fiber reinforced long-cycle autoclave group in comparison with the other test groups $(p<0.05)$.

Conclusions The long-cycle autoclave polymerization technique with the glass fiber reinforcement significantly increased the flexural strength and elastic modulus of the denture base resin material.
\end{abstract}

\section{Introduction}

Polymethyl methacrylate (PMMA) has been ordinarily utilized for denture base construction. ${ }^{1,2}$ Generally, PMMA has good physical properties; it is easy to use and manipulate, simple to process, inexpensive, biocompatible, relatively stable in the oral cavity, and produces acceptable esthetic results. ${ }^{3-5}$ However, different studies have questioned its mechanical properties, particularly its flexural properties due to their brittle nature. ${ }^{4-6}$ Under repeated dynamic loads or accident drop down could result in a prosthesis fracture. ${ }^{7}$

Heat-polymerized PMMA using the water bath procedure has been the technique of choice for most dental practitioners due to its simplicity, ease of manipulation, and inexpensive equipment; however, some limitations of this technique have been proved such as poor mechanical properties. ${ }^{8,9}$ Nevertheless, several studies found that utilizing alternative techniques, such as using a microwave or using an autoclave polymerization process, might improve the mechanical properties of PMMA. ${ }^{10-14}$ Autoclave polymerization was introduced to overcome the drawbacks of the water bath technique. The technique is simple, and it requires less processing time than the water bath technique. Autoclave polymerization protocol depends on increasing the pressure within the enclosed container upon heating, which consequently increases the water temperature above $100^{\circ} \mathrm{C}^{11}$ Ayaz et $\mathrm{al}^{10}$ (2014) reported that autoclave polymerization attained a greater hardness of PMMA and 
contained a lesser content of residual monomer than the conventional water bath technique. The significant raise in the hardness of the PMMA was referred to the major reduction of the residual monomer, which proved to have an influence on the mechanical characteristics of acrylic resin. ${ }^{10,15}$ Durkan et $\mathrm{al}^{11}$ evaluated the effect of the polymerization technique on the transverse strength of denture base resin using the conventional water bath, long-cycle autoclave polymerization techniques. They found that the transverse strength of the acrylic resin increased significantly after using autoclave cycles when compared with the water bath technique. Furthermore, it was noticed that there was no significant difference between the two autoclave polymerization techniques.

In addition, many reinforcement materials have been utilized to enhance PMMA strength. Metal powder, metal plates and wires, rubber agents, nanoparticles, and fibers have been investigated as means to enhance the mechanical properties of acrylic resin. ${ }^{16-20}$ Reinforcing fibers include glass fibers, polyethylene fibers, carbon fibers, nylon fibers, and aramid fibers. ${ }^{20-23}$ However, some of these fibers interrupt the homogeneity of the resin matrix due to poor interaction with the resin that negatively affects the mechanical properties. Furthermore, carbon fibers were considered clinically ineffective due to an unaesthetic color and a difficulty to be polished. ${ }^{24}$ Evidence has shown that polyethylene fibers could cause mucosal irritation when coming out of the acrylic resin surface. $^{25}$

Fiber reinforcement of denture bases through the inclusion of glass fibers in the powder of acrylic resin has shown significantly high strength of the acrylic resin, and is aesthetically accepted due to its colorless property. ${ }^{22,23,26-28}$ Fonseca et $\mathrm{a}^{26}$ incorporated silanized glass fibers into the PMMA resin powder, which exhibited higher flexural strength than the unreinforced acrylic resin. They found a direct link between the content of silanized glass fibers and the flexural strength; where $7 \%$ (by weight) exhibited the highest flexural strength, which decreased as the content of glass fibers decreased.

The impact of the combination process of the autoclave polymerization technique and glass fiber addition on the flexural properties of PMMA has not yet been investigated. Therefore, the goal of this study was to evaluate the effect of the autoclave polymerization technique with glass fiber addition on the flexural strength and elastic modulus of PMMA and compared it with the conventional water bath polymerization technique. The null hypothesis was that the autoclave polymerization techniques with glass fiber reinforcement probably had no significant effect on the flexural strength and elastic modulus of PMMA as compared with the conventional water bath polymerization technique.

\section{Materials and Methods}

\section{Study Designing and Grouping}

Ninety specimens made of heat-polymerized acrylic resin (Major base 20, Prodotti Dentari Spa, Italy) were used for this in vitro investigation. Specimens were randomly distributed based on the heat polymerization technique into three main groups ( $n=30$ per each): a water bath polymerization group, a short-cycle autoclave polymerization group, and a long-cycle autoclave polymerization group. Each group was then divided into three subgroups $(n=10)$ where one subgroup of each main group was kept without reinforcement, while the other two groups were reinforced with 2.5 and $5 \mathrm{wt} \%$ of glass fibers, respectively (-Table $\mathbf{1}$ ).

\section{Mold and Specimens' Preparation}

Following ANSI/ADA specification No.12, metal molds were constructed for a flexural strength test in the desired shape with the dimensions of $65 \times 10 \times 2.5 \pm 0.02 \mathrm{~mm} .{ }^{29}$ Dental wax (Cavex Set Up Wax, Cavex, Netherland) was used to build the shape of the molds and invested in a type III dental stone (GC Fujirock EP, Belgium) using a metal flask (61B Two Flask Compress;, Handler Manufacturing, Westfield, New Jersey, United States). After the dental stone had set, a wax burnt out procedure was performed through immersing the specimens in boiled water for 5 minutes and then molds were washed out and dried. After that, a layer of a separating medium (Isol Major; Major Prodotti Dentari Spa, Moncalieri, Italy) was spread on the inner surfaces of the mold.

For the reinforced specimens, glass fibers (E-glass; length $=3 \mathrm{~mm}$, Shanghai Richem International Co., Ltd., Shanghai, China) were weighted using an electronic scale (S-234; Denver Instrument, Gottingen, Germany) and then added into heat-polymerized acrylic resin powder in concentrations of 2.5 and $5 \mathrm{wt} \%$ of acrylic powder where the whole composite was mixed in a porcelain jar until equal distribution of fibers within the resin powder was achieved. Preweighted glass fibers were treated with 3-trimethoxysilyl propyl methacrylate (TMSPM; Shanghai Richem International Co., Ltd., China) as a silane-coupling agent at room temperature for 1 minute, then added, and mixed with the preweighted acrylic resin powder. ${ }^{30}$ Based on the manufacturer's instructions, the liquid/powder ratio of the resin polymer was mixed using a porcelain container that was kneaded by hand to increase the polymer homogeneity and integrity until reaching the doughy stage where the acrylic resin was then packed into a mold. After that, the flasks were closed for 30 minutes under a pressure of $20 \mathrm{kN} .^{30}$ The whole unit was preserved for 1 hour at room temperature.

Table 1 Polymerization technique, glass fiber reinforcement, and codes for all study groups

\begin{tabular}{|l|l|l|}
\hline Polymerization technique & $\begin{array}{l}\text { Glass fiber } \\
\text { reinforcement }\end{array}$ & Code \\
\hline \multirow{2}{*}{$\begin{array}{l}\text { Water bath-polymerized acrylic } \\
\text { resin }\end{array}$} & $0 w \mathrm{t} \%$ & $\mathrm{WB}$ \\
\cline { 2 - 3 } & $2.5 \mathrm{wt} \%$ & $\mathrm{WB} 2$ \\
\cline { 2 - 3 } & $5 \mathrm{wt} \%$ & $\mathrm{WB} 5$ \\
\hline \multirow{3}{*}{$\begin{array}{l}\text { Short-cycle autoclave polymerized } \\
\text { acrylic resin }\end{array}$} & $0 \mathrm{wt} \%$ & $\mathrm{AS}$ \\
\cline { 2 - 3 } & $2.5 \mathrm{wt} \%$ & $\mathrm{AS} 2$ \\
\hline & $5 w \mathrm{t} \%$ & $\mathrm{AS} 5$ \\
\hline \multirow{2}{*}{$\begin{array}{l}\text { Long-cycle autoclave polymerized } \\
\text { acrylic resin }\end{array}$} & $0 \mathrm{wt} \%$ & $\mathrm{AL}$ \\
\cline { 2 - 3 } & $2.5 \mathrm{wt} \%$ & $\mathrm{AL} 2$ \\
\cline { 2 - 3 } & $5 \mathrm{wt} \%$ & $\mathrm{AL} 5$ \\
\hline
\end{tabular}

Abbreviations: AL, autoclave long; AS, autoclave short; WB, water bath. 
Water Bath and Autoclave Polymerization Techniques

The heat-polymerized specimens of the water bath technique were submerged in a water bath of curing unit (KaVo; Elektrotechnisches Werk, GmbH, Leutkirch, Germany) at room temperature. The processing was done following the manufacturer's guidelines using the conventional curing cycle where specimens processed in at $74^{\circ} \mathrm{C}$ for 2 hours and then $100^{\circ} \mathrm{C}$ for 1 hour.

For the autoclave-polymerized groups, the specimens processed in short cycle were exposed to an autoclave polymerization cycle (Ritter M11 UltraClave; Midmark International, Spain) at $60^{\circ} \mathrm{C}$ for 30 minutes and then at $120^{\circ} \mathrm{C}$ for 10 minutes. For the long-cycle processing technique, the autoclave polymerization was performed at $60^{\circ} \mathrm{C}$ for 30 minutes and followed by $120^{\circ} \mathrm{C}$ for 20 minutes.

After the specimens' polymerization was completed, the flasks were cooled down to room temperature through a bench cool. After deflasking, finishing and polishing procedures were performed in the usual manner and then specimens were inspected to verify the dimensions using a digital caliber. Then, all specimens were kept in distilled water at $37^{\circ} \mathrm{C}$ for 48 hours.

\section{Testing Procedures}

The three-point bending test was used to assess the flexural strength and was conducted in air at $21 \pm 1^{\circ} \mathrm{C}$ using a universal testing machine (Instron 8871; Instron Co. Buckinghamshire, United Kingdom).

Each specimen was positioned on the flexure apparatus, keeping the separation distance at $50 \mathrm{~mm}$ between the supports. A load of $50 \mathrm{kgf}$ was applied at the center of each specimen using a $5 \mathrm{~mm} / \mathrm{min}$ crosshead speed. The load of fracture was recorded and the flexural strength were calculated using the equation $\left(S=3 W L / 2 b d^{2}\right) .^{31} S$ indicates the flexural strength, $W$ is the load to fracture value measured in newton $(\mathrm{N}), L$ presents the separation distance, and $b$ and $d$ are presented the specimen width and thickness, respectively.

To measure the elastic modulus, the equation $E=F L^{3} / 4 b h^{3} d$ was conduced. ${ }^{31} E$ is the value of elastic modulus in MPa, $F$ presents the load $(\mathrm{N})$ at a convenient point $(\mathrm{p})$ of the elastic deformation curve, $L$ the separation distance between the supports, $b$ is the width of the specimen, $h$ is the thickness and $d$ indicated the deflection occurred at point $(p)$.

\section{Scanning Electron Microscope Assessment}

After the flexural strength test was performed for all specimens, the fractured specimens underwent a SEM (Inspect S50; FEI Co., Oregon, United States) evaluation of their fractured sides. The SEM analysis was performed based on the difference in the polymer matrix geometry among the different polymerization techniques as well as the glass fiber reaction within the matrix and its distribution based on the different concentrations. Microphotographs were captured on a standardized magnification of 2,000× for visual inspection and analysis.

\section{Statistical Analysis}

SPSS-20.0 (IBM Product of Chicago, United States) was utilized to analyze the data. The results were presented in terms of arithmetic mean and standard deviation (SD). The one-way ANOVA test was utilized to compare the mean effect of the polymerization techniques and glass fiber reinforcement on the flexure strength and elastic modulus. Post hoc Duncan's multiple-range test was performed to compare the difference of means among various glass fiber reinforcements into a specific polymerization technique as well as among various polymerization techniques into a specific glass fiber reinforcement. The significance level was located when $p$ value $\leq 0.05$.

\section{Results}

\section{Flexural Strength}

- Table 2 shows means and the SD of the flexural strength (MPa) for all the tested groups. Generally, it was noticed that by increasing the percentage of fiber reinforcement from 0 to $2.5 \mathrm{wt} \%$ and from 2.5 to $5 \mathrm{wt} \%$, the flexural strength increased significantly $(p<0.05)$. The tested groups had a statistically significant difference between the means as indicated by one-way ANOVA (F $[2,27]=394.980, p=0.000 ;$ - Table 3). Within the water bath technique groups, the WB5 group presented a significantly higher strength as compared with the WB2 and the WB group $(p=0.000)$. Furthermore, within the short-cycle autoclave technique groups, the AS5 group had a significantly increased flexural strength when compared with the AS2 and AS groups ( $p=0.000$; - Table 3 ). Within the long-cycle autoclave technique groups, AL5 presented statistically significant increase in the flexural strength compared with AL2 and AL groups ( $p=0.000$; - Table 3 ).

Tukey's post hoc test indicated that the flexural strength was significantly higher in the AL5 group in comparison to the other tested groups ( $92.02 \pm 1.05 \mathrm{MPa}, p=0.000$ ), whereas the $\mathrm{WB}$ group showed the lowest value $(77.23 \pm 1.20 \mathrm{MPa}$; $p \leq 0.05$; - Table 4).

\section{Elastic Modulus}

Means and SDs of the modulus elastic values of the different groups are represented in - Table $\mathbf{2}$. The tested groups had a statistically significant difference as indicated by one-way ANOVA $(\mathrm{F}[2,27]=285.754 ; p=0.000 ;$ - Table 5). Within the water bath groups, WB5 group exhibited statistically

Table 2 Mean and standard deviation of the flexural strength and elastic modulus of the tested groups

\begin{tabular}{|l|l|l|}
\hline Tested group & $\begin{array}{l}\text { Flexural strength } \\
\text { (Mean } \pm \text { SD) }\end{array}$ & $\begin{array}{l}\text { Elastic modulus } \\
\text { (Mean } \pm \text { SD) }\end{array}$ \\
\hline WB & $77.23 \pm 1.20$ & $2067.08 \pm 11.03$ \\
\hline WB2 & $79.99 \pm 0.58$ & $2173.27 \pm 5.40$ \\
\hline WB5 & $82.86 \pm 0.49$ & $2273.98 \pm 5.71$ \\
\hline AS & $82.27 \pm 0.72$ & $2114.44 \pm 2.62$ \\
\hline AS2 & $86.15 \pm 0.66$ & $2217.25 \pm 2.00$ \\
\hline AS5 & $87.92 \pm 0.49$ & $2324.29 \pm 8.00$ \\
\hline AL & $84.27 \pm 0.59$ & $2172.24 \pm 16.31$ \\
\hline AL2 & $88.85 \pm 1.19$ & $2282.25 \pm 7.04$ \\
\hline AL5 & $92.02 \pm 1.05$ & $2355.29 \pm 8.95$ \\
\hline
\end{tabular}

Abbreviations: AL, autoclave long; AS, autoclave short; WB, water bath. 
Table 3 One-way ANOVA test for flexural strength within the polymerization technique groups

\begin{tabular}{|c|c|c|c|c|}
\hline Polymerization technique & \multicolumn{2}{|c|}{ Glass fiber reinforcement } & Mean difference & $p$-Value \\
\hline \multirow[t]{3}{*}{ WB } & $5 \%$ & $0 \%$ & 5.64 & $0.000^{\mathrm{a}}$ \\
\hline & $5 \%$ & $2.5 \%$ & 2.87 & $0.000^{\mathrm{a}}$ \\
\hline & $2.5 \%$ & $0 \%$ & 2.77 & $0.000^{\mathrm{a}}$ \\
\hline \multirow[t]{3}{*}{ AS } & $5 \%$ & $0 \%$ & 5.65 & $0.000^{\mathrm{a}}$ \\
\hline & $5 \%$ & $2.5 \%$ & 1.77 & $0.000^{\mathrm{a}}$ \\
\hline & $2.5 \%$ & $0 \%$ & 3.88 & $0.000^{\mathrm{a}}$ \\
\hline \multirow[t]{3}{*}{ AL } & $5 \%$ & $0 \%$ & 7.75 & $0.000^{\mathrm{a}}$ \\
\hline & $5 \%$ & $2.5 \%$ & 3.17 & $0.000^{\mathrm{a}}$ \\
\hline & $2.5 \%$ & $0 \%$ & 4.58 & $0.000^{\mathrm{a}}$ \\
\hline
\end{tabular}

aStatistically significant at $p \leq 0.05$.

Table 4 Tukey's post hoc multiple comparisons test for the flexural strength of the acrylic resins

\begin{tabular}{|l|l|l|}
\hline $\begin{array}{l}\text { Tested } \\
\text { group }\end{array}$ & Mean \pm SD & SSD \\
\hline WB & $77.23 \pm 1.20$ & $\begin{array}{l}\text { WB2, WB5, AS, AS2, AS5, AL, AL2, } \\
\text { AL5 }\end{array}$ \\
\hline WB2 & $79.99 \pm 0.58$ & $\begin{array}{l}\text { WB, WB5, AS, AS2, AS5, AL, AL2, } \\
\text { AL5 }\end{array}$ \\
\hline WB5 & $82.86 \pm 0.49$ & $\begin{array}{l}\text { WB, WB2, AS, AS2, AS5, AL, AL2, } \\
\text { AL5 }\end{array}$ \\
\hline AS & $82.27 \pm 0.72$ & $\begin{array}{l}\text { WB, WB2, WB5, AS2, AS5, AL, } \\
\text { AL2, AL5 }\end{array}$ \\
\hline AS2 & $86.15 \pm 0.66$ & $\begin{array}{l}\text { WB, WB2, WB5, AS, AS5, AL, AL2, } \\
\text { AL5 }\end{array}$ \\
\hline AS5 & $87.92 \pm 0.49$ & $\begin{array}{l}\text { WB, WB2, WB5, AS, AS2, AL, AL2, } \\
\text { AL5 }\end{array}$ \\
\hline AL & $84.27 \pm 0.59$ & $\begin{array}{l}\text { WB, WB2, WB5, AS, AS2, AS5, } \\
\text { AL2, AL5 }\end{array}$ \\
\hline AL2 & $88.85 \pm 1.19$ & $\begin{array}{l}\text { WB, WB2, WB5, AS, AS2, AS5, } \\
\text { AL, AL5 }\end{array}$ \\
\hline AL5 & $92.02 \pm 1.05$ & $\begin{array}{l}\text { WB, WB2, WB5, AS, AS2, AS5, } \\
\text { AL, AL2 }\end{array}$ \\
\hline
\end{tabular}

Abbreviations: SD, standard deviation; SSD, statistically significant difference.

Note: SSD from the tested group at $p \leq 0.05$ level of significance.

Multiple comparison tests for all pairwise differences between means. significant higher flexural strength as compared with WB2 and WB groups ( $p=0.000)$. Elastic modulus was significantly higher in AS5 as compared with AS2 and AS groups when the comparison made within the short-cycle autoclave groups $(p=0.000)$ as shown in - Table 5 .

A Tukey's post hoc test showed that the elastic modulus was statistically significantly higher in AL5 (2355.29 \pm 8.95 MPa; $p=0.000$ ) as compared with the other test groups, while WB group presented significantly the lowest elastic modulus value (2067.08 MPa; $p \leq 0.05$; - Table 6).

\section{Analysis of SEM Micro-Images}

Microphotos from the SEM show the resin matrix and the impeded glass fibers in the fractured sides of the specimens among the tested groups ( - Fig. 1). All microimages included in the study were captured at a magnification of 2,000×. It can be noticed in - Fig. 1A that the resin matrix is less homogeneous and contains irregular patterns of fracture lines and voids, while - Fig. 1B displays that the crack line propagation within the matrix resin ended at the horizontally positioned glass fibers. - Fig. 1C exhibits spaces of deattached glass fibers. - Fig. 1D shows more homogenous matrix with less voids and less irregular fracture lines. -Fig. 1E exhibits several spaces of deattached glass fibers, which remained attached to the resin matrix in the other side of the fracture

Table 5 One-way ANOVA test for elastic modulus within the polymerization technique groups

\begin{tabular}{|c|c|c|c|c|}
\hline \multirow{2}{*}{$\begin{array}{l}\text { Polymerization technique } \\
\text { WB }\end{array}$} & \multicolumn{2}{|c|}{ Glass fiber reinforcement } & \multirow{2}{*}{$\begin{array}{l}\text { Mean difference } \\
206.91\end{array}$} & \multirow{2}{*}{$\begin{array}{l}p \text {-Value } \\
0.000^{\text {a }}\end{array}$} \\
\hline & $5 \%$ & $0 \%$ & & \\
\hline & $5 \%$ & $2.5 \%$ & 100.72 & $0.000^{\mathrm{a}}$ \\
\hline & $2.5 \%$ & $0 \%$ & 106.19 & $0.000^{\mathrm{a}}$ \\
\hline \multirow[t]{3}{*}{ AS } & $5 \%$ & $0 \%$ & 209.84 & $0.000^{\mathrm{a}}$ \\
\hline & $5 \%$ & $2.5 \%$ & 107.03 & $0.000^{\mathrm{a}}$ \\
\hline & $2.5 \%$ & $0 \%$ & 102.81 & $0.000^{\mathrm{a}}$ \\
\hline \multirow[t]{3}{*}{$\mathrm{AL}$} & $5 \%$ & $0 \%$ & 183.04 & $0.000^{\mathrm{a}}$ \\
\hline & $5 \%$ & $2.5 \%$ & 73.03 & $0.000^{\mathrm{a}}$ \\
\hline & $2.5 \%$ & $0 \%$ & 110.01 & $0.000^{\mathrm{a}}$ \\
\hline
\end{tabular}

aStatistically significant at $p \leq 0.05$. 
Table 6 Tukey's post hoc multiple comparisons test for the elastic modulus of the acrylic resins

\begin{tabular}{|l|l|l|}
\hline $\begin{array}{l}\text { Tested } \\
\text { group }\end{array}$ & Mean \pm SD & SSD \\
\hline WB & $2067.08 \pm 11.03$ & $\begin{array}{l}\text { WB2, WB5, AS, AS2, AS5, AL, } \\
\text { AL2, AL5 }\end{array}$ \\
\hline WB2 & $2173.27 \pm 5.40$ & $\begin{array}{l}\text { WB, WB5, AS, AS2, AS5, AL, } \\
\text { AL2, AL5 }\end{array}$ \\
\hline WB5 & $2273.98 \pm 5.71$ & $\begin{array}{l}\text { WB, WB2, AS, AS2, AS5, AL, } \\
\text { AL2, AL5 }\end{array}$ \\
\hline AS & $2114.44 \pm 2.62$ & $\begin{array}{l}\text { WB, WB2, WB5, AS2, AS5, AL, } \\
\text { AL2, AL5 }\end{array}$ \\
\hline AS2 & $2217.25 \pm 2.00$ & $\begin{array}{l}\text { WB, WB2, WB5, AS, AS5, AL, } \\
\text { AL2, AL5 }\end{array}$ \\
\hline AS5 & $2324.29 \pm 8.00$ & $\begin{array}{l}\text { WB, WB2, WB5, AS, AS2, AL, } \\
\text { AL2, AL5 }\end{array}$ \\
\hline AL & $2172.24 \pm 16.31$ & $\begin{array}{l}\text { WB, WB2, WB5, AS, AS2, AS5, } \\
\text { AL2, AL5 }\end{array}$ \\
\hline AL2 & $2282.25 \pm 7.04$ & $\begin{array}{l}\text { WB, WB2, WB5, AS, AS2, AS5, } \\
\text { AL, AL5 }\end{array}$ \\
\hline AL5 & $2355.29 \pm 8.95$ & $\begin{array}{l}\text { WB, WB2, WB5, AS, AS2, AS5, } \\
\text { AL, AL2 }\end{array}$ \\
\hline
\end{tabular}

Abbreviations: SD, standard deviation; SSD, statistically significant difference.

Note: Multiple comparison tests for all pairwise differences between means. SSD from the tested group at $p \leq 0.05$ level of significance.

line. - Fig. 1F shows the tendency of glass fibers to form clusters during the resin polymerization. -Fig. 1G exhibits more homogenous matrix with some grooves while - Fig. 1H and 1I show fractured and clustered glass fibers.

\section{Discussion}

While PMMA has been shown to possess inadequacies, such as a low flexural strength due to repeated denture base flexing under continuous biting forces, it has been considered the preferred material to construct removable prostheses due its biocompatibility, adequate aesthetic results, and ease of preparation and manipulation. ${ }^{6,11}$ Different techniques have been utilized to strengthen the structure of PMMA and to improve its mechanical properties. These techniques included adding fibers to the PMMA powder and modifying the polymerization procedures either by using a different methodology, such as an autoclave technique and a microwave technique, or by changing the polymerization process time..$^{10,13,19}$

The goal of this in vitro study was to assess the impact of glass fiber reinforcement and the autoclave polymerization technique on the flexural strength and elastic modulus of the heat-polymerized acrylic resin material. The null hypothesis was rejected as the fiber reinforcement with the long-cycle autoclave polymerization technique significantly and positively enhanced the flexural strength and elastic modulus of the heat-polymerized acrylic resin.

As a term, autoclave has been used to describe the elevation of temperature and pressure in sealed vessels to process materials based on raising the water boiling point above $100^{\circ} \mathrm{C}$ to the point at which the volume of the container remains constant. ${ }^{11}$ The autoclave technique was initially invented as a tool for sterilization in 1879 by Charles Chamberland. ${ }^{32}$ Abdulwahhab $^{33}$ reported that the autoclave polymerization improved the impact strength and the hardness of acrylic denture base resins.

In this study, the autoclave polymerization technique had a significant impact on the flexural strength of the acrylic resins with and without the glass fiber reinforcement, especially the long-cycle autoclave group when it was compared with the water bath technique. However, the long-cycle autoclave polymerization technique with glass fiber reinforcement significantly had an impact on the flexural strength and elastic modulus as compared with the same cycle without fiber reinforcement.

The result of this study is in agreement with other studies that showed a significant impact of the autoclave polymerization technique on the flexural strength of the acrylic resin. Ayaz et $\mathrm{al}^{10}$ reported that the autoclave polymerization technique presented significantly higher hardness than the conventional water bath technique. They attributed this result to the significant decrease in the residual monomer content as compared with the conventional technique. Moreover, different studies have shown the negative impact of high residual monomer content, which can act as a plasticizer. A plasticizing change in the resin polymer can result in a disintegration of the polymer's chains, which can lower its resistance against deformation. ${ }^{34,35}$

Glass fibers are inorganic materials related to alumina-lime-borosilicate. They have a reinforcement advantage due to its resistance to the heat and chemicals and have good mechanical properties. Moreover, they have a low surface energy due to its hydrophobic nature and it is less susceptible to oral cavity moisture. ${ }^{19,28}$ Treating the surface of glass fibers with a silane-coupling agent increases the fibers' impregnation into the PMMA powder matrix, which increases the resin strength. ${ }^{19}$

The result of the present study was coincident with different studies that showed that glass fiber reinforcement had a favorable impact on the mechanical properties of the acrylic resins. ${ }^{22,23,36}$ Moreno-Maldonado et $\mathrm{al}^{36}$ found that the glass fibers strengthened the PMMA in comparison to the polyethylene fibers. This strengthening was referred to the chemical adhesion of silane to the glass fiber structure, which made the glass fibers adhere better to PMMA polymer matrix. ${ }^{35}$ However, this positive impact of glass fibers has been affected by different factors, like the fibers' orientation, fibers' concentration, and fibers' integration into the PMMA. ${ }^{36,37}$ Furthering this research, the result of this study displayed that the flexural strength and elastic modulus increased by increasing the concentration of glass fibers despite of the polymerization technique due the fibers' stiffness that exceeded the surrounding polymer matrix, which allowed it to withstand the flexural strength as compared with the nonreinforced acrylic resins.

In addition, by applying the load on the specimen, the tension occurred below the long axis of the specimen. Thus, glass fibers likely reduced the flexure of the specimen because of the increased chemical boning of the glass fibers, 


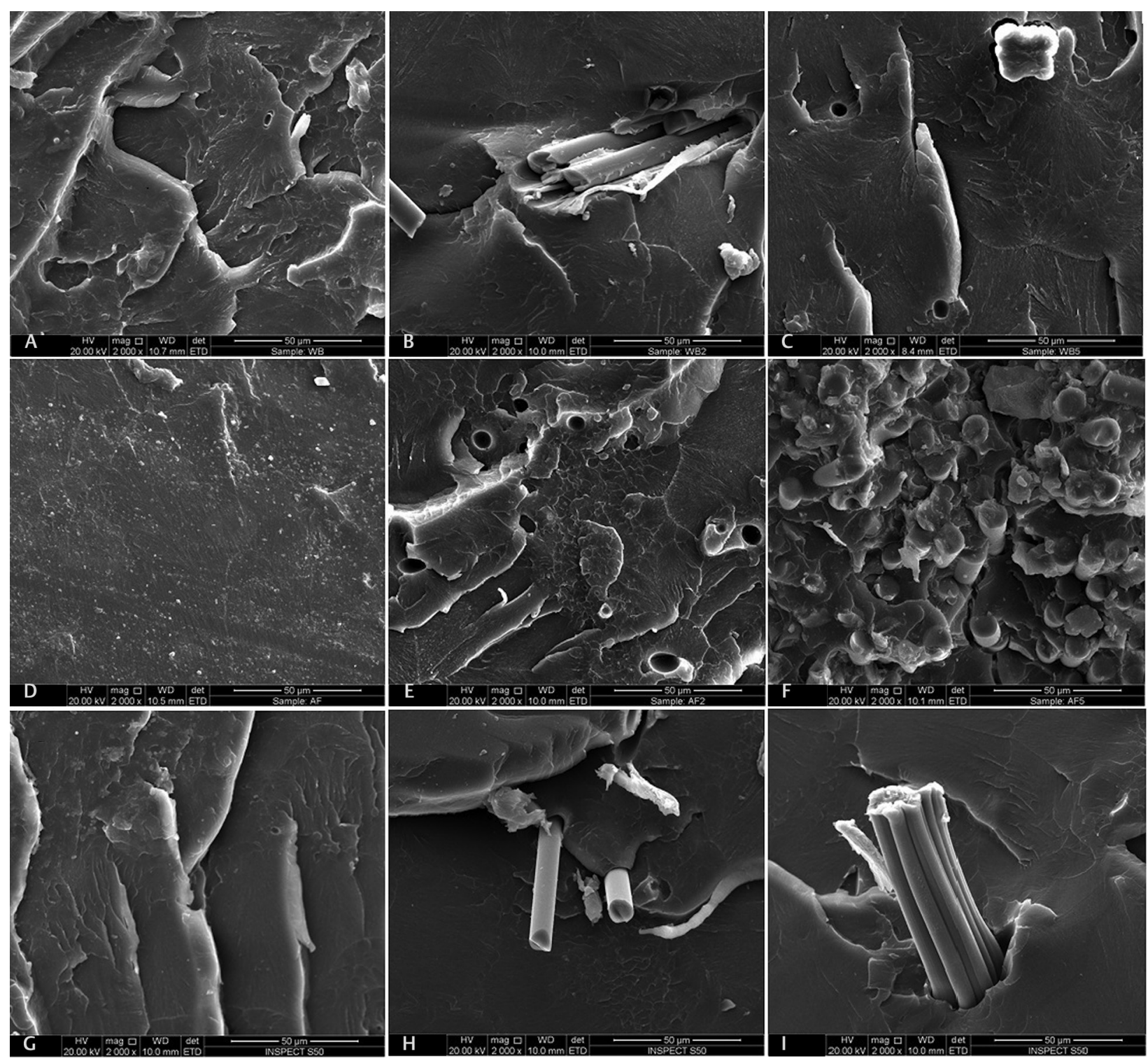

Fig. 1 Scanning electron microscopy images representing specimens of the tested groups at the fractured side. (A) WB group, (B) WB2 group, (C) WB5 group, (D) AS group, (E) AS2 group, (F) AS5 group, (G) AL group, (H) AL2 group, and (I) AL5 group.

and the fibers' thickness reduced the elongation of the polymer matrix. Inanaga et $\mathrm{al}^{38}$ and Shimozato et $\mathrm{al}^{39}$ reported the same result when the flexural strength of the carbon fibers reinforced acrylic resin was investigated.

The SEM photographs revealed that glass fibers have stopped the lengthening of the resin matrix during the flexural strength test, which resulted in improvement in the flexural strength of the specimens. In - Fig. 1B the crack propagation ended at the glass fiber which may indicate the significant increase of flexural strength of reinforced specimens after the addition of glass fibers. - Fig. 1F, 1I show the cluster formation of glass fibers during the resin polymerization, which could offer an advantage to increasing the resin strength. Furthermore, it has been noted that the complete fracture of the specimens occurred in instances when the glass fibers have fractured. The fracture of the glass fibers occurred at a different level than the resin matrix after the fiber bending, which could explain the apparent fracture resistance these fibers provided to the resin. The photographs show a good contact between the resin matrix and glass fibers, which could be referred to the wetting of the fibers using the saline-coupling agent. $^{26}$

As the elastic modulus test shows the ability of the acrylic resin to resist the elastic deformation, the result of this study exhibited that the glass fiber reinforcement improved the elastic modulus of the resin. Nagai et $\mathrm{al}^{40}$ reported that the glass fibers significantly improved the elastic modulus of the repaired acrylic resin. They found that the pretreatment of the fibers surface with methylene chloride positively affected the elastic modulus of the reinforced specimens.

The study limitations included the different environment represented in the laboratory setting as compared with the clinical settings where the moisture of the oral cavity could affect the behavior of the material. In addition, the material 
designing and sample preparation were different than the actual construction of dental prostheses. However, clinical studies need to be performed to prove the result of this study.

Clinical implications: in this study, the combination of glass fiber reinforcement and the autoclave polymerization technique revealed a significant increase in the mechanical properties of PMMA as compared with the results of the water bath technique with or without the fiber reinforcement. In addition, this combination had a positive influence on the flexural strength of the acrylic resin as compared with the autoclave polymerization technique without glass fiber reinforcement. Moreover, the results of this study recommended reinforcing complete and partial dentures with glass fibers as well as using the long-cycle autoclave polymerization technique to increase the durability of these prostheses.

\section{Conclusions}

Counting the limitations of the present study, the long-cycle autoclave polymerization technique with $5 \mathrm{wt} \%$ glass fiber reinforcement had a significant higher flexural strength and elastic modulus in comparison to other groups. It could be recommended that the combination of glass fiber reinforcement and long-autoclave polymerization technique is a useful protocol improving the mechanical properties of heat polymerized acrylic resin.

\section{Conflict of Interest}

None declared.

\section{Acknowledgment}

Author would like to acknowledge Mr. Ashwin Shetty for helping in the statistical analysis and Mr. Lensey Mateo for his support in mechanical testing.

\section{References}

1 Narva KK, Lassila LV, Vallittu PK. The static strength and modulus of fiber reinforced denture base polymer. Dent Mater 2005;21(5):421-428

2 Polychronakis N, Yannikakis S, Zissis A. A clinical 5-year longitudinal study on the dimensional changes of complete maxillary dentures. Int J Prosthodont 2003;16(1):78-81

3 Nejatian T, Johnson A, Van Noort R. Reinforcement of denture base resin. Advances in Science and Technology 2006;49:124-129

4 Meng TR Jr, Latta MA. Physical properties of four acrylic denture base resins. J Contemp Dent Pract 2005;6(4):93-100

5 Narendra R, Reddy NS, Reddy SD, Purna CR, Shekar MC, Balasubramanyam S. A comparative evaluation of impact strength of conventionally heat cured and high impact heat cured polymethyl methacrylate denture base resins: an in vitro study. J Contemp Dent Pract 2013;14(6):1115-1121

6 Jagger DC, Harrison A, Jandt KD. The reinforcement of dentures. J Oral Rehabil 1999;26(3):185-194

7 Kanie T, Fujii K, Arikawa H, Inoue K. Flexural properties and impact strength of denture base polymer reinforced with woven glass fibers. Dent Mater 2000;16(2):150-158

8 Price CA. The effect of cross-linking agents on the impact resistance of a linear poly(methyl methacrylate) denture-base polymer. J Dent Res 1986;65(7):987-992
9 Winkler S. Denture base resins. Dent Clin North Am 1984;28(2):287-297

10 Ayaz EA, Durkan R, Koroglu A, Bagis B. Comparative effect of different polymerization techniques on residual monomer and hardness properties of PMMA-based denture resins. J Appl Biomater Funct Mater 2014;12(3):228-233

11 Durkan R, Ozel MB, Bağiş B, Usanmaz A. In vitro comparison of autoclave polymerization on the transverse strength of denture base resins. Dent Mater J 2008;27(4):640-642

12 Kasina SP, Ajaz T, Attili S, Surapaneni H, Cherukuri M, Srinath HP. To evaluate and compare the porosities in the acrylic mandibular denture bases processed by two different polymerization techniques, using two different brands of commercially available denture base resins - an in vitro study. J Int Oral Health 2014;6(1):72-77

13 Ozkir SE, Yilmaz B, Unal SM, Culhaoglu A, Kurkcuoglu I. Effect of heat polymerization conditions and microwave on the flexural strength of polymethyl methacrylate. Eur J Dent 2018;12(1):116-119

14 Lai CP, Tsai MH, Chen M, Chang HS, Tay HH. Morphology and properties of denture acrylic resins cured by microwave energy and conventional water bath. Dent Mater 2004;20(2):133-141

15 Frangou MJ, Polyzois GL. Effect of microwave polymerisation on indentation creep, recovery and hardness of acrylic denture base materials. Eur J Prosthodont Restor Dent 1993;1(3):111-115

16 Ruffino AR. Effect of steel strengtheners on fracture resistance of the acrylic resin complete denture base. J Prosthet Dent 1985;54(1):75-78

17 Gad MM, Rahoma A, Al-Thobity AM, ArRejaie AS. Influence of incorporation of $\mathrm{ZrO}_{2}$ nanoparticles on the repair strength of polymethyl methacrylate denture bases. Int J Nanomedicine 2016;11:5633-5643

18 Vallittu PK, Lassila VP. Effect of metal strengthener's surface roughness on fracture resistance of acrylic denture base material. J Oral Rehabil 1992;19(4):385-391

19 Mowade TK, Dange SP, Thakre MB, Kamble VD. Effect of fiber reinforcement on impact strength of heat polymerized polymethyl methacrylate denture base resin: in vitro study and SEM analysis. J Adv Prosthodont 2012;4(1):30-36

20 Vallittu PK, Vojtkova H, Lassila VP. Impact strength of denture polymethyl methacrylate reinforced with continuous glass fibers or metal wire. Acta Odontol Scand 1995;53(6):392-396

21 Gutteridge DL. The effect of including ultra-high-modulus polyethylene fibre on the impact strength of acrylic resin. $\mathrm{Br}$ Dent J 1988;164(6):177-180

22 Vallittu PK. Glass fiber reinforcement in repaired acrylic resin removable dentures: preliminary results of a clinical study. Quintessence Int 1997;28(1):39-44

23 Hamouda IM, Beyari MM. Addition of glass fibers and titanium dioxide nanoparticles to the acrylic resin denture base material: comparative study with the conventional and high impact types. Oral Health Dent Manag 2014;13(1):107-112

24 Ekstrand K, Ruyter IE, Wellendorf H. Carbon/graphite fiber reinforced poly(methyl methacrylate): properties under dry and wet conditions. J Biomed Mater Res 1987;21(9):1065-1080

25 Foo SH, Lindquist TJ, Aquilino SA, Schneider RL, Williamson DL, Boyer DB. Effect of polyaramid fiber reinforcement on the strength of 3 denture base polymethyl methacrylate resins. J Prosthodont 2001;10(3):148-153

26 Fonseca RB, Favarao IN, Kasuya AVB, Abrao M, Luz NFM, Navez LZ. Influence of glass fiber Wt\% and silanization on mechanical flexural strength of reinforced acrylic. J of Mat Sci and Chem 2014;2:11-15

27 Geerts GA, Overturf JH, Oberholzer TG. The effect of different reinforcements on the fracture toughness of materials for interim restorations. J Prosthet Dent 2008;99(6):461-467 
28 John J, Gangadhar SA, Shah I. Flexural strength of heat-polymerized polymethyl methacrylate denture resin reinforced with glass, aramid, or nylon fibers. J Prosthet Dent 2001;86(4):424-427

29 Revised American Dental Association specification no. 12 for denture base polymers. J Am Dent Assoc 1975;90(2):451-458

30 Gad MM, Al-Thobity AM, Rahoma A, Abualsaud R, Al-Harbi FA, Akhtar S. Reinforcement of PMMA denture base material with a mixture of $\mathrm{ZrO}_{2}$ nanoparticles and glass fibers. Int J Dent 2019;2019:2489393

31 International Organization for Standardization. Dentistry-base polymers - Part 1: denture base polymers. Volume 20795-1. Geneva: ISO; 2008

32 Chamberland C. Chronological reference marks. Paris: Pasteur Institute; 2007:1-19

33 Abdulwahhab SS. High-impact strength acrylic denture base material processed by autoclave. J Prosthodont Res 2013;57(4):288-293

34 Farina AP, Cecchin D, Soares RG, et al. Evaluation of Vickers hardness of different types of acrylic denture base resins with and without glass fibre reinforcement. Gerodontology 2012;29(2):e155-e160
35 Hayden WJ. Flexural strength of microwave-cured denture baseplates. Gen Dent 1986;34(5):367-371

36 Moreno-Maldonado V, Acosta-Torres LS, Barceló-Santana FH, Vanegas-Lancón RD, Plata-Rodríguez ME, Castaño VM. Fiber-reinforced nanopigmented poly (methyl methacrylate) as improved denture base. J Appl Polym Sci 2012;126:289-296

37 Uzun G, Hersek N, Tinçer T. Effect of five woven fiber reinforcements on the impact and transverse strength of a denture base resin. J Prosthet Dent 1999;81(5):616-620

38 Inanaga $\mathrm{A}$, Naka S, Takahashi Y, et al. Studies on denture base resins reinforced with carbon or aramid fiber. Part 1 . The effectiveness of including fiber and surface treatments. J Jpn Prosthodont Soc 1993;37:1083-1090

39 Shimozato T, Yamanaka A, Kurata S, Yamazaki N. Denture base PMMA resins reinforced with carbon fibers. Part 1. Surface treatments of the carbon fibers and its effects on flexural and tensile strength of the reinforced resins. J Jpn Soc Dent Mater Device 1984;3:648-654

40 Nagai E, Otani K, Satoh Y, Suzuki S. Repair of denture base resin using woven metal and glass fiber: effect of methylene chloride pretreatment. J Prosthet Dent 2001;85(5):496-500 